\title{
Abstracted Model for Ceramic Coating
}

Joseph C. Farmer

Christine Stockman

November 14, 1998

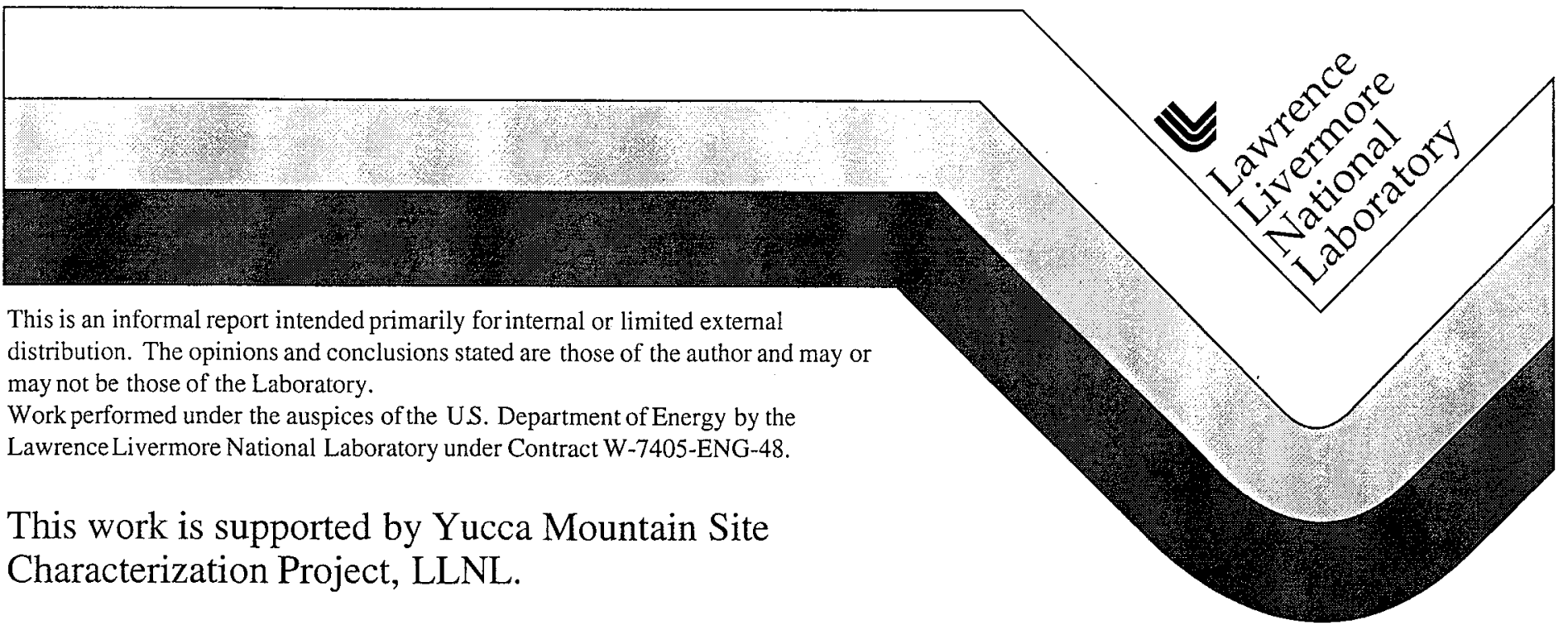




\section{DISCLAIMER}

This document was prepared as an account of work sponsored by an agency of the United States Government. Neither the United States Government nor the University of California nor any of their employees, makes any warranty, express or implied, or assumes any legal liability or responsibility for the accuracy, completeness, or usefulness of any information, apparatus, product, or process disclosed, or represents that its use would not infringe privately owned rights. Reference herein to any specific commercial product, process, or service by trade name, trademark, manufacturer, or otherwise, does not necessarily constitute or imply its endorsement, recommendation, or favoring by the United States Government or the University of California. The views and opinions of authors expressed herein do not necessarily state or reflect those of the United States Government or the University of California, and shall not be used for advertising or product endorsement purposes.

This report has been reproduced directly from the best available copy.

Available to DOE and DOE contractors from the Office of Scientific and Technical Information

P.O. Box 62, Oak Ridge, TN 37831

Prices available from (615) 576-8401, FTS 626-8401

Available to the public from the

National Technical Information Service

U.S. Department of Commerce

5285 Port Royal Rd.,

Springfield, VA 22161 


\section{Calculation Title:}

Document Identifier:

Originators:

Checker:

Lead Discipline Engineer: R. Daniel McCright, Chemistry and Materials Science Department, University of California, Lawrence Livermore National Laboratory, Mail Stop L-369, 7000 East Avenue or P.O. Box 808, Livermore, California 94550, Telephone 925-422-7051, Fax 925423-2118, E-mail <mccright1@llnl.gov>

Department Manager: David Stahl, Framatome-Cogema Fuels, 1180 Town Center Drive, Las Vegas, Nevada 89134, Telephone 702-295-4383, Fax 702295-4438, E-mail <david_stahl@notes.ymp.gov>

Draft Date: $\quad$ Saturday, November 14, 1998 (original) 


\section{Purpose}

Engineers are exploring several mechanisms to delay corrosive attack of the CAM (corrosion allowance material) by dripping water, including drip shields and ceramic coatings. Ceramic coatings deposited with high-velocity oxyfuels (HVOF's) have exhibited a porosity of only $2 \%$ at a thickness of $0.15 \mathrm{~cm}$. The primary goal of this document is to provide a detailed description of an abstracted process-level model for Total System Performance Assessment (TSPA) that has been developed to account for the inhibition of corrosion by protective ceramic coatings. A second goal was to address as many of the issues raised during a recent peer review as possible (direct reaction of liquid water with carbon steel, stress corrosion cracking of the ceramic coating, bending stresses in coatings of finite thickness, limitations of simple correction factors, etc.). During the periods of dry oxidation $\left(\mathrm{T} \geq 100^{\circ} \mathrm{C}\right)$ and humid-air corrosion $\left(\mathrm{T} \leq 100^{\circ} \mathrm{C} \&\right.$ $\mathrm{RH}<80 \%$ ), it is assumed that the growth rate of oxide on the surface is diminished in proportion to the surface covered by solid ceramic. The mass transfer impedance imposed by a ceramic coating with gas-filled pores is assumed to be negligible. During the period of aqueous phase corrosion $\left(\mathrm{T} \leq 100^{\circ} \mathrm{C} \& \mathrm{RH} \geq 80 \%\right.$ ), it is assumed that the overall mass transfer resistance governing the corrosion rate is due to the combined resistance of ceramic coating $\&$ interfacial corrosion products. Two porosity models (simple cylinder \& cylinder-sphere chain) are considered in estimation of the mass transfer resistance of the ceramic coating. It is evident that substantial impedance to $\mathrm{O}_{2}$ transport is encountered if pores are filled with liquid water. It may be possible to use a sealant to eliminate porosity. Spallation (rupture) of the ceramic coating is assumed to occur if the stress introduced by the expanding corrosion products at the ceramicCAM interface exceeds fracture stress. Since this model does not account for the possibility of corrosion products filling pores, it is believe to be very conservative. In such a case, the corrosion product would not spread across the ceramic-CAM interface and no spallation would occur. Thus, the coating would be expected to last indefinitely.

\section{Method}

\subsection{Corrosion Reactions}

It is assumed that the corrosion reaction at the interface between the ceramic and carbon steel is limited by oxygen availability and results in the formation of $\mathrm{Fe}_{3} \mathrm{O}_{4}$. The overall corrosion reaction is represented by Equation 1 [Eqn. 2b Ref. 7.1]:

$$
3 \mathrm{Fe}+2 \mathrm{O}_{2} \longrightarrow \mathrm{Fe}_{3} \mathrm{O}_{4}
$$

\subsection{Flux of Oxygen to Interface}

The average flux of oxygen per unit area of waste package, $J$, is given by Equation 2 [Eqn. 13 Ref. 7.1]: 
$J=\frac{\theta_{I} D_{I}}{\delta}\left(C_{s a t}-C_{i}\right)$

where $\theta_{I}$ is the fraction of the CAM exposed to the aqueous phase at the ceramic-CAM interface, $D_{I}$ is the bulk diffusivity of the corrodant in the pore, $C_{i}$ is the concentration of dissolved oxygen at the ceramic-CAM interface, $C_{s a t}$ is the concentration of dissolved oxygen at the outer surface of the ceramic coating, and $\delta$ is the thickness of the ceramic coating. The parameter $\theta_{I}$ is interpreted as porosity. Values of $0.02-0.03$ have been achieved with HVOF ceramic coatings having thicknesses of approximately $1.5 \mathrm{~mm}$. Thus far, thicker coatings have been significantly more porous.

In reality, the pores in the ceramic coating are not as simple as portrayed in the above straight hollow cylinder visualization. Actually, the pores in ceramic coatings can be better represented by an array of chains, each link being composed of a hollow sphere and a relatively narrow hollow cylinder, connected in series. A more precise representation has been developed by Hopper, which has become known as the cylinder-sphere chain (CSC) porosity model. In this case, the flux is diminished by a correction factor, $f(\varepsilon, \lambda)$, where $\varepsilon$ and $\lambda$ are dimensionless parameters used to further characterize the porous structure [Eqn. 17 Ref. 7.1]:

$f(\varepsilon, \lambda)=\frac{3}{2} \frac{(1+\lambda)^{2}}{\lambda} \varepsilon^{2}$

Here the dimensionless parameters $\varepsilon$ and $\lambda$ represent the geometry of the sphere-cylinder chain [Eqns. 19-22 Ref. 7.1]:

$\varepsilon=\frac{\text { diameter of cylinder in chain }}{\text { diameter of sphere in chain }}$

$\lambda=\frac{\text { length of cylinder in chain }}{\text { diameter of sphere in chain }}$

Reasonable estimates for $\varepsilon$ and $\lambda$, based on actual microstructures, are as follows:

$0.01 \leq \varepsilon \leq 0.10$

$2 \leq \lambda \leq 10$

\subsection{Penetration Rates - No Ceramic Coating}


The penetration $(p)$ as a function of time $(t)$ and temperature $(T)$ is based on the correlation used in TSPA, given here as Equation 8 [Eqn. 5-13 Ref. 7.2].

$$
\ln \left(D_{g}\right)=b_{0}+b_{1} \ln (t)+\frac{b_{2}}{T}+b_{3} T^{2}+\bar{\varepsilon}
$$

The penetration used in Ref. $7.1(p)$ is related to that used in Ref. 7.2 $\left(D_{g}\right)$ by Equation 9:

$$
p=G \times D_{G}
$$

where $G$ is the constant factor for converting units of $\left(\mu \mathrm{m} \mathrm{y}^{-1}\right)$ to $\left(\mathrm{cm} \mathrm{s}^{-1}\right)$. Similarly, the penetration rates in the two references are related by:

$$
\left(\frac{d p}{d t}\right)_{0}=G \times\left(\frac{d D_{G}}{d t}\right)_{0}
$$

where the subscript (0) denotes rates in the absence of the ceramic coating.

\subsection{Penetration Rate with Ceramic Coating (g-factor)}

If no mass transfer impedance is imposed by the interfacial corrosion product, the penetration rate $(d p / d t)$ is constant and the penetration $(p)$ increases linearly with time $(t)$. In such a case, a simple time-independent correction factor $(g)$ can be used to account for the inhibition of the corrosion process by the porous ceramic coating. This approach is represented by Equation 11 [Eqn. 62 Ref. 7.1].

$$
\frac{d p}{d t}=g \times\left(\frac{d p}{d t}\right)_{0}
$$

The correction factor is defined by Equation 12 [Eqn. 61 Ref. 7.1]:

$$
g=\frac{1}{1+\left(\frac{\delta k_{0}}{\theta_{I} D_{I}}\right)\left(\frac{1}{f(\varepsilon, \lambda)}\right)}
$$

A plausible scenario leading to a time-independent correction factor assumes that the corrosion product accumulated at the interface imposes no significant mass transport limitation (coating dominates). Regardless of whether or not the interfacial corrosion product ultimately imposes a significant mass transfer impedance (thereby causing long-term parabolic dependence of penetration on time), the short-term dependence of penetration can be approximated as linear 
function of time (constant penetration rate). Such an approximation has been shown to be valid at times prior to coating spallation. This "g-factor" approach (model abstraction) should enable those involved in TSPA to evaluate the benefits of protective ceramic coatings quickly and efficiently:

It is necessary to express the correction factor in Equation 12 in terms of the penetration rate in the absence of the ceramic coating. This is done by first noting that the reaction rates of oxygcn and iron are related by Equation 13, which is based upon the stoichiometry of Equation 1:

$$
\frac{d\left[\mathrm{O}_{2}\right]}{d t}=\frac{2}{3} \frac{d[\mathrm{Fe}]}{d t}
$$

The heterogeneous reaction of $\mathrm{O}_{2}$ at the interface between the ceramic coating and the CAM is detcrmined by the interfacial concentration, which is limited by transport through the ceramic coating as shown by Equation 14 [Eqn. 58 Ref. 7.1]:

$$
\frac{1}{A} \frac{d\left[O_{2}\right]}{d t}=k_{0} C_{i}=\frac{\left(C_{s a t}-C_{i}\right)}{\delta} D_{I} \theta_{I} f(\varepsilon, \lambda)
$$

The rate of reaction of iron is related to the penetration rate by Equation 15:

$$
\frac{d[F e]}{d t}=\frac{\rho}{w} \times A \times\left(\frac{d p}{d t}\right)_{0}
$$

The relationship between the penetration rate $(d p / d t)_{0}$ and the apparent rate constant $\left(k_{0}\right)$ is derived by substituting Equations 14 and 15 into Equation 13:

$\left(\frac{d p}{d t}\right)_{0}=\frac{3}{2} \frac{w}{\rho} k_{0} C_{s a t}$

Rearrangement yields:

$$
k_{0}=\left(\frac{d p}{d t}\right)_{0} /\left(\frac{3}{2} \frac{w}{\rho} C_{s a t}\right)
$$

Substitution of Equation 17 into Equation 12 yields Equation 18:

$$
g=\frac{1}{1+\left(\frac{d p}{d t}\right)_{0}\left(\frac{2 \rho \delta}{\left.3 w \theta_{I} \frac{2 \rho C_{I} C_{s a t} f(\varepsilon, \lambda)}{D^{\prime}}\right)}\right.}
$$


Substitution of Equation 10 into Equation 18 yields Equation 19:

$$
g=\frac{1}{1+G\left(\frac{d D_{g}}{d t}\right)_{0}\left(\frac{2 \rho \delta}{3 w O_{I} D_{I} C_{s a l} f(\varepsilon, \lambda)}\right)}
$$

This is applied to Equation 20, which is a variation of Equation 11:

$$
\frac{d D_{g}}{d t}=g \times\left(\frac{d D_{g}}{d t}\right)_{0}
$$

Finally, by combining Equations 19 and 20, one obtains Equation 21:

$$
\frac{d D_{g}}{d t}=\left(\frac{d D_{g}}{d t}\right)_{0} \div\left\{1+G\left(\frac{d D_{g}}{d t}\right)_{0}\left(\frac{2 \rho \delta}{3 w \theta_{I} D_{I} C_{s a t} f(\varepsilon, \lambda)}\right)\right\}
$$

\subsection{Spallation of the Ceramic Coating}

Spallation may occur at a blister, such as the one shown in Attachment 8.8 of Reference 7.1. In this case, it is assumed that the blister can be modeled as a deflected circular plate with fixed edges. Thus, Roark's formulas can be used [Eqns. 79-84 Ref. 7.1]. The deflection of the center of the circular plate from the relaxed position is $y_{c}$, defined as follows:

$$
y_{c}=-\frac{q a^{4}}{64 D}
$$

where $q$ is the uniform load (pressure) exerted on the internal surface of the deflected circular plate (blister), $a$ is the radius of the circular plate (blister), and $D$ is the plate constant. The plate constant is given by:

$$
D=-\frac{E t^{3}}{12\left(1-v^{2}\right)}
$$

where $E$ is the elastic modulus of the ceramic coating, $t$ is the thickness of the plate, and $v$ is Poisson's ratio. The thickness of the plate is equivalent to the coating thickness, $\delta$. Note that $t$ represents time in other equations. The thickness variable $t$ has not been redefined in equation 23 so that it is completely consistent with published references. The bending moment at the center of the plate is $\mathrm{M}_{\mathrm{c}}$, defined as follows: 
$M_{c}=\frac{q a^{2}(1+v)}{16}$

The stress on the concave surface of the deflected circular plate is compressive, and the stress on the convex surface of the deflected circular plate is tensile. The tensile stress is calculated from $M_{c}$ with the following formula:

$\sigma=\frac{6 M_{c}}{t^{2}}$

Substitution of Equations 22 through 24 into Equation 25 and rearrangement yields Equation 26:

$y_{c}=\frac{1}{2} \frac{\sigma}{E} \frac{a^{2}}{t} \frac{\left(1-v^{2}\right)}{(1+v)}$

The difference between the oxide thickness and the wall penetration $(x-p)$ is defined as the interfacial displacement, and is related to the plate deflection $\left(y_{c}\right)$ by Equation 27 :

$y_{c}=x-p$

The wall penetration $p$ and the oxide thickness $x$ are then related by Equation 28 [Eqn. 6 Ref. 7.1]:

$x=\frac{1}{3}\left(\frac{\rho}{\rho_{0}} \frac{w_{0}}{w}\right) p$

where $\rho$ is the density of the carbon steel (iron), $\rho_{0}$ is the density of the iron oxide (corrosion product), $w$ is the effective atomic weight of the carbon steel (iron), and $w_{0}$ is the formula weight of the iron oxide (corrosion product). The interfacial displacement and plate deflection (blister height) are related by Equation 29:

$y_{c}=x-p=p \times\left\{\frac{1}{3} \frac{\rho}{w} \frac{w_{0}}{\rho_{0}}-1\right\}$

By substituting Equation 29 into Equation 26, one obtains Equation 30:

$p=\left\{\frac{1}{2} \frac{\sigma}{E} \frac{a^{2}}{t} \frac{\left(1-v^{2}\right)}{(1+v)}\right\} \div\left\{\frac{1}{3} \frac{\rho}{w} \frac{w_{0}}{\rho_{0}}-1\right\}$

Farmer \& Stockman, November 14, 1998, UNCLASSIFIED

University of California, Lawrence LivermoreNational Laboratory

7000 East Avenue, Livermore, California 94550 
By substituting Equation 9 into Equation 30, one obtains Equation 31:

$$
D_{g}=\frac{1}{G}\left\{\frac{1}{2} \frac{\sigma}{E} \frac{a^{2}}{t} \frac{\left(1-v^{2}\right)}{(1+v)}\right\} \div\left\{\frac{1}{3} \frac{\rho}{w} \frac{w_{0}}{\rho_{0}}-1\right\}
$$

A Rankine-type failure (maximum normal stress theory) is assumed when the stress in the coating exceeds the fracture stress. This is used to define a critical penetration depth at which the ceramic coating is assumed to rupture (point of spallation).

$$
D_{g}^{*}=\frac{1}{G}\left\{\frac{1}{2} \frac{\sigma^{*}}{E} \frac{a^{2}}{t} \frac{\left(1-v^{2}\right)}{(1+v)}\right\} \div\left\{\frac{1}{3} \frac{\rho}{w} \frac{w_{0}}{\rho_{0}}-1\right\}
$$

The time that lapses before spallation of the ceramic coating (time-to-failure) is defined as:

$$
t_{f}^{*}=\frac{D_{g}^{*}}{g \times\left(d D_{g} / d t\right)_{0}}
$$

\subsection{Alternative Abstraction for Penetration Rate (limiting flux)}

If the penetration rate is at the mass transport limit, the interfacial concentration $\left(C_{i}\right)$ will be zero. Equations 14 and 16 are combined to yeild Equation 34:

$$
\frac{d p}{d t}=\frac{3}{2} \frac{w}{\rho}\left\{\frac{C_{\text {sat }} D_{I} \theta_{I}}{\delta}\right\} f(\varepsilon, \lambda)
$$

Equation 35 is obtained by substituting Equation 9 into Equation 34 .

$$
\frac{d D_{g}}{d t}=\frac{1}{G}\left[\frac{3}{2} \frac{w}{\rho}\left\{\frac{C_{s a t} D_{I} \theta_{I}}{\delta}\right\} f(\varepsilon, \lambda)\right]
$$

In this case, the time-to-failure is defined by Fquation 36 :

$$
t_{f}^{*}=\frac{D_{g}^{*}}{d D_{g} / d t}
$$

It should be noted that Equation 35 is completely consistent with Equation 21 in the limit where $(d p / d t)_{0} \rightarrow \infty$, which is equivalent to saying that there is no interfacial mass transfer 
impedance. The primary advantage of Equation 21 is that the interfacial concentration is not assumed to be zero.

\section{Assumptions}

Assumptions are summarized as follows:

3.1 Aqueous phase corrosion is limited by the diffusion of dissolved $\mathrm{O}_{2}$ through water in the pores of both the ceramic coating.

3.2 It is assumed that the pores are filled with water (liquid).

3.3 The aqueous phase corrosion rate is proportional to the concentration of dissolved oxygen, and is essentially zero in a completely deaerated (oxygen-free) solution.

3.4 The reaction between water and the carbon steel is insignificant.

3.5 If the interfacial corrosion product is assumed to impose no significant mass transport limitation.

3.6 The interfacial oxide is magnetite, which is assumed to be able to exert more compressive force than the oxyhydroxides. This is believed to be a conservative assumption.

3.7 The ceramic coating fails when the maximum tensile stress due to the accumulation of corrosion products exceeds the measured fracture strain (Rankine-type failure mechanism or maximum normal stress theory).

3.8 The blister radius is the same size as a standard WAPDEG patch (Ref. 7.2).

3.9 The time-to-failure obeys a $\log$ normal distribution.

3.10 The minimum and maximum estimates of the time-to-failure, calculated with the parameter ranges given in Table 1, correspond to the values at $\pm 4 \sigma$.

3.11 These extremes are assumed to define the $0^{\text {th }}$ and $100^{\text {th }}$ percentiles.

\section{Use of Computer Software}

No computer codes were written for this model abstraction.

\section{Calculations}

\subsection{Calculation Inputs}

The parameters given in Table 1 are used in these equations. The critical penetration is estimated to be $26.37 \mu \mathrm{m}$ if the fracture strain is assumed to be $16.7 \mathrm{MPa}$ and $271.6 \mu \mathrm{m}$ if the fracture strain is $172 \mathrm{MPa}$. Based on Equation 8, the penetration is estimated to be $107.8 \mu \mathrm{m}$ after 1 year at $100^{\circ} \mathrm{C}$, and $152.6 \mu \mathrm{m}$ after 1 year at $25^{\circ} \mathrm{C}$. This is a very surprising result, since one usually expects rates to increase with temperature. 
Table 1. Parameter Values

\begin{tabular}{|l|}
$G=3.1710 \times 10^{-12} \mathrm{~cm} \mathrm{~s}^{-1} \mu m^{-1} y$ \\
$b_{0}=111.53$ \\
$b_{1}=0.53199$ \\
$b_{2}=-23291$ \\
$b_{3}=-3.1918 \times 10^{-4}$ \\
$\bar{\varepsilon}=0.0362$ \\
$\delta=0.15 \mathrm{~cm}$ \\
$a=5 \mathrm{~cm}$ \\
$\lambda=2-10$ \\
$\varepsilon=0.01-0.10$ \\
$E=356 \mathrm{GPa}$ \\
$v=0.26$ \\
$\sigma^{*}=16.7-172 \mathrm{MPa}$ \\
$C_{s a t}=1.26 \times 10^{-3} \mathrm{~mol} \mathrm{~cm}^{-3}$ \\
$\theta_{I}=0.02$ \\
$D_{I}=3.00 \times 10^{-5} \mathrm{~cm}^{2} \mathrm{~s}^{-1}$ \\
$w=55.847$ \\
$w_{0}=231.54$ \\
$\rho=7.86 \mathrm{~g} \mathrm{~cm}^{-3}$ \\
$\rho_{0}=5.18 \mathrm{~g} \mathrm{~cm}^{-3}$
\end{tabular}

\subsection{Calculation Procedure}

Equation 8 is used to calculate the penetration at 1 year and $100^{\circ} \mathrm{C}$.

$$
\ln \left(D_{g}\right)=b_{0}+b_{1} \ln (t)+\frac{b_{2}}{T}+b_{3} T^{2}+\bar{\varepsilon}
$$

The rate is estimated from the value of Dg calculated with Equation 8:

$$
\left(\frac{d D_{g}}{d t}\right)_{0} \approx \frac{D_{g}}{t}
$$


The effect of the ceramic coating on the penetration rate is accounted for through application of Equation 19, the penetration rate correction factor:

$$
g=\frac{1}{1+G\left(\frac{d D_{g}}{d t}\right)_{0}\left(\frac{2 \rho \delta}{3 w \theta_{I} D_{I} C_{\text {sat }} f(\varepsilon, \lambda)}\right)}
$$

where the porosity correction factor is defined by Equation 3:

$$
f(\varepsilon, \lambda)=\frac{3}{2} \frac{(1+\lambda)^{2}}{\lambda} \varepsilon^{2}
$$

This penetration rate correction factor is applied to the penetration rate based upon Equation 18:

$$
\frac{d D_{g}}{d t}=g \times\left(\frac{d D_{g}}{d t}\right)_{0}
$$

The critical penetration at which the ceramic coating is assumed to undergo spallation is calculated with Equation 32:

$D_{g}^{*}=\frac{1}{G}\left\{\frac{1}{2} \frac{\sigma^{*}}{E} \frac{a^{2}}{t} \frac{\left(1-v^{2}\right)}{(1+v)}\right\} \div\left\{\frac{1}{3} \frac{\rho}{w} \frac{w_{0}}{\rho_{0}}-1\right\}$

Therefore, the time-to-failure based on the g-factor model is defined by Equation 33:

$$
t_{f}^{*}=\frac{D_{g}^{+}}{g \times\left(d D_{g} / d t\right)_{0}}
$$

Alternatively, the time-to-failure based on the limiting flux model defined by Equation 36:

$$
t_{f}^{*}=\frac{D_{g}^{*}}{d D_{g} / d t}
$$

where the penetration rate is given by Equation 35:

$$
\frac{d D_{g}}{d t}=\frac{1}{G}\left[\frac{3}{2} \frac{w}{\rho}\left\{\frac{C_{s a t} D_{I} \theta_{I}}{\delta}\right\} f(\varepsilon, \lambda)\right]
$$




\section{Results}

Equation 3 and the values in Table 1 are used to generate the range of values in Table 2.

Table 2. Expected Range of Correction Factors for Penetration Rates

\begin{tabular}{|l|l|l|l|}
\hline$\varepsilon$ & $\lambda$ & $f(\varepsilon, \lambda)$ & $g$ \\
\hline 0.01 & 2 & $6.00 \times 10^{-4}$ & $9.43 \times 10^{-5}$ \\
\hline 0.10 & 2 & $6.00 \times 10^{-2}$ & $9.35 \times 10^{-3}$ \\
\hline 0.01 & 10 & $1.08 \times 10^{-3}$ & $1.70 \times 10^{-4}$ \\
\hline 0.10 & 10 & $1.08 \times 10^{-1}$ & $1.67 \times 10^{-2}$ \\
\hline
\end{tabular}

Equation 33 and the values in Tables 1 and 2 are used to generate the time-to-failure in Table 3 .

Table 3. Expected Range of Failure Times

\begin{tabular}{|l|l|l|l|l|l|}
\hline & g-factor & g-factor & g-factor & limiting flux & limiting flux \\
\hline$D_{g}{ }^{*}$ & $g$ & $\left(d D_{g}{ }^{*} / d t\right)_{0}$ & $t_{f}{ }^{*}$ & $d D_{g}{ }^{*} / d t$ & $t_{f}{ }^{*}$ \\
\hline$\mu \mathrm{m}$ & none & $\mu \mathrm{m} \mathrm{y}^{-1}$ & years & $\mu \mathrm{m} \mathrm{y}^{-1}$ & years \\
\hline 26.37 & $9.43 \times 10^{-3}$ & 107.8 & 2,589 & $1.0164 \times 10^{-2}$ & 2,594 \\
\hline 26.37 & $9.35 \times 10^{-3}$ & 107.8 & 15 & 1.0164 & 26 \\
\hline 271.6 & $1.70 \times 10^{-4}$ & 107.8 & 26,668 & $1.8295 \times 10^{-2}$ & 14,846 \\
\hline 271.6 & $1.67 \times 10^{-2}$ & 107.8 & 151 & 1.8295 & 148 \\
\hline
\end{tabular}

As expected, the two alternative abstractions, referred to as "g-factor" and "limiting flux" give comparable results. The lowest and highest values of the logarithm of the time-to-failure $\left(\ln t_{f}^{*}\right)$ are assumed to be normally distributed. These values are further assumed to define the $0^{\text {th }}$ and $100^{\text {th }}$ percentiles (values at $\pm 4 \sigma$ ). The cummulative distribution functions (CDF's) in Table 4 are therefore established. These CDF's depend upon the specific assumptions that are made pertaining to the shapes of the distributions. If different assumptions are made, the distributions will be changed accordingly. 
Table 4. Estimated Distribution of Failure Times

\begin{tabular}{|l|l|l|l|l|}
\hline & g-factor & g-factor & limiting flux & limiting flux \\
\hline Percentile & $\ln t_{f}{ }^{*}$ & $t_{f}{ }^{*}$ & $\ln t_{f}{ }^{*}$ & $t_{f}{ }^{*}$ \\
\hline$\%$ & $\ln$ (years) & years & $\ln$ (years) & years \\
\hline 0 & 2.71 & 15 & 3.26 & 26 \\
\hline 1 & 3.64 & 38 & 4.05 & 58 \\
\hline 5 & 4.58 & 98 & 4.85 & 127 \\
\hline 50 & 6.45 & 633 & 6.43 & 622 \\
\hline 95 & 8.32 & 4,105 & 8.02 & 3,026 \\
\hline 99 & 9.26 & 10,509 & 8.81 & 6,684 \\
\hline 100 & 10.19 & 26,668 & 9.61 & 14,846 \\
\hline
\end{tabular}

The two approaches give essentially the same value at the $50^{\text {th }}$ percentile. These $50^{\text {th }}$ percentile estimates are in close agreement with those previously published. For example, the range of values determined from Attachment 8.9 of Reference 7.1 is 500 to 7,000 years (representative of $5^{\text {th }}$ and $95^{\text {th }}$ percentiles). A time-to-failure of approximately 14,037 years is given in Table 2.8-9 of Reference 7.3. The values given in References 7.1 and 7.3 are consistent with the bounding estimates given in Reference 7.4 .

\section{References}

7.1 J. Farmer, K. Wilfinger, "Process Level Ceramics Model," UCRL-ID-131899, Rev. 1 \& 2, University of California, Lawrence Livermore National Laboratory, Livermore, $\mathrm{C} \Lambda$ 94550, October 12 \& November 14, 1998.

7.2 J. Lee et al., "Waste Package Degradation Modeling and Abstraction," Chapter 5, in Total System Performance Assessment-Viability Assessment (TSPA-VA), B0000000001717-4301-00005 Rev. 0, TRW Environmental Safety Systems, Inc., 1261 Town Center Drive, Las Vegas, NV 89314, August 14, 1998, pp. 5-40 through 5-66.

7.3 J.C. Farmer, "Corrosion Model Development," Section 2.8, in Engineered Materials Characterization Report (EMCR), UCRL-ID-119564, Vol. 3, Rev. 1.1, R.D. McCright, Editor, University of California, Lawrence Livermore National Laboratory, Livermore, CA 94550, 1998, pp. 2.8-4 through 2.8-11, Tables 2.8-1 and 2.8-3.

7.4 J. C. Farmer, "Development of Corrosion Models to Support TSPA-VA: Protective Ceramic Coatings," in Protective Ceramic Coatings for High-Level Radioactive Waste Containers, UCRL-MI-131293, University of California, Lawrence Livermore National Laboratory, Livermore, CA 94550, August 17, 1998, 44 p. with inserts.

\section{Attachments}

No attachments are included. 